Published in final edited form as:

Fertil Steril. 2020 February ; 113(2): 392-399. doi:10.1016/j.fertnstert.2019.09.030.

\title{
Reproductive Intentions in Childless Female Adolescent and Young Adult Cancer Survivors
}

\author{
Christina M. Lam, MD, \\ Department of Obstetrics, Gynecology \& Reproductive Science, University of California, San \\ Diego, La Jolla, CA
}

Ksenya Shliakhtsitsava, MD, MAS,
Department of Pediatric Hematology/Oncology, University of Texas Southwestern, Dallas, TX

Shaylyn S. Stark, MPH,

Moores Cancer Center, University of California, San Diego, La Jolla, CA

\author{
Alexa C.O. Medica, MD, \\ Department of Obstetrics, Gynecology \& Reproductive Science, University of California, San \\ Diego, La Jolla, CA
}

\section{Kelsey A. Pinson, MD,}

Department of Obstetrics, Gynecology \& Reproductive Science, University of California, San Diego, La Jolla, CA

\section{Brian W. Whitcomb, PhD, \\ Department of Biostatistics \& Epidemiology, School of Public Health \& Health Sciences, University of Massachusetts, Amherst, MA \\ H. Irene Su, MD, MSCE \\ Department of Obstetrics, Gynecology \& Reproductive Science and Moores Cancer Center, University of California, San Diego, La Jolla, CA}

\section{Abstract}

Objective: To examine the association between prior cancer treatments, medical comorbidities, and voluntary childlessness in reproductive-aged women who are survivors of cancers diagnosed as adolescents and young adults (AYA survivors).

Design: Cross-sectional.

Setting: Participants were recruited from California and Texas cancer registries, fertility preservation programs, and cancer advocacy groups.

Corresponding Author: H. Irene Su, MD MSCE, 3855 Health Sciences Drive, Dept 0901, La Jolla, CA 92093-0901, Fax: 858-246-0822, Tel: 858-822-0768, hisu@ucsd.edu.

Publisher's Disclaimer: This is a PDF file of an unedited manuscript that has been accepted for publication. As a service to our customers we are providing this early version of the manuscript. The manuscript will undergo copyediting, typesetting, and review of the resulting proof before it is published in its final form. Please note that during the production process errors may be discovered which could affect the content, and all legal disclaimers that apply to the journal pertain.

Conflict of Interest: There are no conflicts of interest to disclose for any authors. 
Patients: Women ( $\mathrm{n}=413)$ aged 18-40, diagnosed with cancer between ages 15-35, completed primary cancer treatments, had at least one ovary, and were nulliparous.

Exposure: Cancer treatment gonadotoxicity and medical comorbidities.

Main outcome measure: Voluntary childlessness.

Results: Mean age of survivors was 31.8 years (SD 4.9) with a mean of 6.5 years (SD 4.4) since cancer diagnosis. Breast (26\%), thyroid (19\%), and Hodgkin lymphoma (18\%) were the most common cancers. Twenty-two percent of the cohort was voluntarily childless. Medical comorbidities, cancer diagnosis, prior surgery, prior chemotherapy, and prior gonadotoxic treatments were not significantly associated with voluntary childlessness. In adjusted analysis, survivors of older reproductive age (aOR $2.97(1.71-5.18), \mathrm{p}<0.01)$ and non-heterosexual participants (aOR $4.71(2.15-10.32), \mathrm{p}<0.01)$ were more likely to report voluntary childlessness.

Conclusions: A moderate proportion of AYA cancer survivors is voluntarily childless, but reproductive intentions were not related to cancer type or cancer treatments. AYA survivors of older age and non-heterosexual identification were more likely to be voluntarily childless. These data support assessing reproductive intentions and tailoring reproductive care, i.e. fertility and contraception counseling, appropriate for a survivor's intentions.

\section{Capsule:}

One-fifth of female adolescent and young adult cancer survivors is voluntarily childless. Voluntary childlessness was not related to cancer characteristics, supporting assessing reproductive intentions across survivors and individualizing reproductive care.

\section{Keywords}

Voluntary childlessness; young adult; cancer; survivor

\section{Introduction}

In the United States, there are nearly 400,000 reproductive-aged, female cancer survivors (1). Fertility has been identified as an important aspect of survivorship and quality of life, but studies have demonstrated that female cancer survivors are 50-75\% as likely to have biological children compared with the general female population (2-7). While lower birth rates may be due to infertility following cancer treatments (8-10), the unique reproductive concerns of cancer survivors, such as concerns about personal health during pregnancy or negative impact of parental cancer on offspring health, add complexity to reproductive choice and potentially contribute to decisions not to have children $(3,11-14)$.

Voluntary childlessness, defined by the National Survey of Family Growth (NSFG) as "those who expect to have no children in their lifetimes and are either physically able to have a birth or surgically sterile for contraceptive reasons", is self-reported by approximately $6 \%$ of females in the U.S. general population (15). Among childless women in the NSFG survey, voluntarily childless women were more likely to be older, currently married, and white compared to women who expect to have one or more children in the future (15). Another 
study derived from the NSFG also found that lesbian women were less likely to express desire for parenthood compared to matched heterosexual females (16).

In other chronic disease states, voluntary childlessness rates are higher when compared to the general population. Studies of patients with multiple sclerosis (MS) and inflammatory bowel disease (IBD) have found higher rates of voluntary childlessness compared to the general population (17-20). Similar to cancer survivors, participants in these studies voiced reproductive concerns including worries about their illness interfering with parenting, disease inheritance, and physical disability (17-18). A longitudinal study in the United Kingdom demonstrated that a higher proportion of childless women (17.1\%) had a longterm illness compared with mothers who did not have a limiting long-term illness (11.7\%), although voluntary and involuntary childlessness were not able to be distinguished in this study (21).

While many studies on cancer survivors focus on desired childbearing, voluntary childlessness has not been previously studied in this population. Thus, the goal of the study was to identify characteristics of reproductive-aged female survivors diagnosed as adolescents or young adults (AYA survivors) that are associated with voluntary childlessness. First, we hypothesized that the cancer treatment burden is associated with voluntary childlessness among female AYA survivors. In addition, because survivors have expressed concerns about their personal health during pregnancy and as parents, we hypothesized that medical comorbidities are also associated with voluntary childlessness.

\section{Materials and methods}

\section{Study population}

A cross-sectional analysis was conducted using enrollment questionnaire data from the Reproductive Window Study, which recruited female AYA survivors to a prospective cohort study on ovarian function after cancer treatment. Participants were recruited from the California and Texas Cancer Registries (32.2\%), University of California, San Diego Health System (30.0\%), cancer advocacy organizations (12.7\%), physician referrals $(7.4 \%)$, and other sources (17.7\%). Eligibility criteria for the parent study included: cancer diagnosis between ages 15-35, 18-40 years of age at study enrollment, completion of primary cancer treatment, and presence of at least one ovary. The following cancer types were included: breast, blood, leukemia, lymphoma, gynecologic (cervix, uterus, ovary), intestines, gallbladder, pancreas, bone, soft tissue tumor of bone/fat, skin, and thyroid. The current analysis was restricted to Window Study participants recruited between 2015 and 2018 who were nulliparous and had primary medical records for cancer treatment abstracted, in order to study voluntary childlessness and its relationship to cancer treatment exposures.

All participants provided informed consent, were asked to provide HIPAA consent to obtain their primary cancer treatment records, and completed questionnaires through a web-based study portal. The State of California Committee for the Protection of Human Subjects and the Institutional Review Boards at the University of California, San Diego and the Texas Department of State Health Services approved this study. 


\section{Data collection}

Data were derived from both self-report and primary cancer treatment records from the questionnaire we administered at the enrollment time point. Participants completed an enrollment questionnaire to report demographic, medical history, cancer and treatment characteristics, reproductive history, and desire for future children. Sexual orientation was assessed using the same question as used in the NSFG: "Do you think of yourself as..." with the following response options: "heterosexual or straight", "homosexual or lesbian", "bisexual" or "prefer not to answer" (22). Participants were also asked to self-report current medical issues including asthma/lung disease, hypertension, diabetes, thyroid disease, psychiatric disorders, rheumatologic diseases, inflammatory bowel disease (Crohn's disease and ulcerative colitis), osteopenia/osteoporosis, seizures, coronary heart disease/heart failure, or stroke.

Self-reported cancer and cancer treatment characteristics included the following: cancer diagnosis, years since diagnosis, and history of prior surgery, chemotherapy and/or radiation as part of cancer treatment. Primary cancer treatment records were obtained, from which cancer diagnosis, chemotherapy regimens and cumulative doses, radiation regimens, location and doses, and surgical procedures were abstracted. We then assigned exposure status for known gonadotoxic treatments: any abdomino-pelvic radiation, total body irradiation, alkylating chemotherapy, or autologous or allogeneic stem cell transplant (9-10, 23).

The desire for future children was assessed using questions derived from the National Survey of Family Growth (NSFG), 2006-2010 cycle (15). The question read, "We would like to know your feelings about having (a/another) baby, whether or not you are able to, or plan to have one. If it were possible, would you want to have a baby at some time in the future?" Participants were able to respond "yes", "no", or "not sure". Participants who responded "not sure", were then prompted to answer the following question, "Do you think you probably would want or probably would not want to have a (another) baby at some time in the future?" Voluntary childless participants were defined as those who did not or probably did not want to have a child in the future, which was modeled after the NSFG questionnaire (15).

\section{Statistical analysis}

The primary outcome was voluntary childlessness. The exposures of interest were cancer treatment toxicity and medical comorbidities. Exposure to gonadotoxic treatments, such as alkylating chemotherapy and abdomino-pelvic radiation, was used as a surrogate for overall cancer treatment toxicity. Alkylating agents are commonly used as part of the treatment regimen for solid and hematologic malignancies and pelvic radiation therapy is often reserved in situations when it cannot be avoided to achieve cure. These treatment modalities have been associated with higher rates infertility in female childhood cancer survivors (8). Participants who were not exposed to gonadotoxic treatments were those who underwent surveillance only, non-gynecologic surgeries, unilateral oophorectomy, radioactive iodine treatment, non-alkylating chemotherapy or radiation to sites other than the abdomen or pelvis. Given the low prevalence of medical comorbidities in our cohort, comorbidities were grouped into none, 1 , or $\geq 2$ comorbidities. 
Categorical variables were summarized by frequencies and proportions. The distributions of continuous variables were assessed for normality and reported as mean (SD) or median (range). Bivariable analyses were conducted using Chi-square tests of proportions or Fisher's Exact tests. Multivariable logistic regression modeling was used to examine the association between the primary exposures of interest $(0,1$ or $\geq 2$ medical comorbidities and high vs. not high treatment gonadotoxicity) and the outcome, while adjusting for confounding. Variables associated with the outcome with a p-value $<0.1$ in bivariable analysis were considered as possible confounders and were included in the multivariable model. As self-reported chemotherapy was co-linear with treatment gonadotoxicity, we included the more accurate medical record derived gonadotoxicity variable in the primary adjusted model and generated separate adjusted models with the patient reported chemotherapy or surgery variables (24). All analyses were conducted using SPSS statistical software v25 (25).

\section{Results}

Of 887 parent study participants, 350 were multiparous and 124 did not have primary medical records available, resulting in 413 nulliparous AYA survivors in this analysis. The mean age (standard deviation [SD]) of survivors at enrollment was 31.8 (4.9) years with a mean of 6.5 (4.4) years since cancer diagnosis. Most participants were white (73\%) and partnered (54.2\%). The most common cancer types were breast (26\%), thyroid (19\%), and Hodgkin lymphoma (18\%). The most common medical comorbidities were mental health disorders (25.7\%), thyroid disorders (17.2\%) and pulmonary conditions (10.4\%). Nine percent of participants self-identified as non-heterosexual. Overall, $22 \%$ of participants were voluntarily childless.

In bivariable analyses, several cancer characteristics differed between AYA survivors who desired children compared to those who were voluntarily childless (Table 1). Exposure to gonadotoxic cancer treatments and chemotherapy were associated with a lower likelihood of voluntary childlessness, while prior surgery was associated with a higher likelihood. Cancer diagnosis, radiation therapy, and medical comorbidities were not associated with voluntary childlessness. Among demographic and reproductive characteristics (Table 2), AYA survivors who were older at the time of enrollment, nulligravid, or identified as nonheterosexual were more likely to be voluntarily childless compared to those who were younger, had prior pregnancy, or identified as heterosexual. Race, Hispanic ethnicity, partnered status, and infertility history were not associated with voluntary childlessness.

A multivariable logistic regression model adjusting for age, sexual identification, and gravidity found that prior gonadotoxic cancer treatment was not significantly associated with voluntarily childlessness (aOR 0.60, 95\% CI 0.35-1.02) (Table 3). Older reproductive age of 36-40, compared to age 25-35, had three-fold higher odds of voluntary childlessness (aOR 2.97, 95\% CI 1.71-5.18), while non-heterosexual identification had a 4.7 fold higher odds (95\% CI 2.15-10.32). In a separate logistic regression model adjusting for age, nonheterosexual identification and gravidity, neither self-reported surgery nor self-reported chemotherapy was significantly associated with voluntary childlessness (Table 4). 


\section{Discussion}

In our study cohort, more than one-fifth of female AYA cancer survivors self-reported voluntary childlessness. Contrary to our hypothesis, cancer treatments, treatment toxicity, and medical comorbidities were not associated with voluntary childlessness, after adjusting for confounding factors. AYA survivors of older age or non-heterosexual identification were more likely to report that they did not wish to have biological children in the future, compared with younger survivors or survivors who self-identify as heterosexual.

These data indicate that parenthood is not a goal for every AYA survivor. While clinical guideline-supported fertility risk discussions throughout the cancer continuum have increased implementation (26), our findings also support the need for appropriate contraception care for individuals who do not wish to have biological children. We and others have shown that AYA survivors contracept less frequently and less effectively than the general population (27-29). Moreover, provider awareness of voluntary childlessness among AYA survivors may impact how and with what frequency fertility needs are assessed in survivorship to minimize patient burden from repeated discussions if they are sure in their decision to be voluntarily childless.

A systemic review by Schmidt et al. provides an overview of patient-reported concerns regarding post-cancer parenthood, which contribute to decisions to live a childfree life (3). Among the most common concerns were those that involved the child's health, specifically that the child may be at higher risk for cancer themselves or may have poorer health if born after cancer (30-31). The validity of these medical concerns varies by prior cancer treatment exposures, but most data are reassuring that children born of cancer survivors are not at higher risk of birth defects, chromosomal abnormalities, or childhood cancer (32-35). However, misperceptions of these risks have been shown, motivating future studies on whether accurate counseling on reproductive risks would modify reproductive intentions (3, $31)$.

Overall, the observations from this study are consistent with that of the general population. Large population-based studies from both the United States and Europe have demonstrated that older women are more likely to be voluntarily childless $(15,36)$. There has also been robust research on the higher rates of voluntary childlessness in the non-heterosexual population (37-38). According to a report published by Gates et al. (2007), 41\% of lesbian women and $52 \%$ of gay men desire children, similar to the proportion observed in our cohort (48.6\%) (39). Research specifically on non-heterosexual individuals suggest several reasons for voluntarily childlessness, including accepting a more open definition of "family" and being flexible to alternative methods of family building (i.e. adoption) (16). Healthcare provider screening and awareness of sexual orientation of AYA survivors may help to guide family building counseling.

Our study specifically addressed voluntary childlessness in a young population of AYA survivors, contributing novel data to this area. We did not observe cancer type, medical comorbidities, or treatment gonadotoxicity to be related to AYA survivors' reproductive intentions after adjusting for confounding factors. These findings are consistent with the two 
previously published studies on cancer treatment exposures and reproductive intentions, one on adult survivors and another on childhood survivors (40-41). Among 175 French female survivors of adult cancers who were not sterilized, menopausal or infertile, the majority of whom were older than age $40,73.7 \%$ reported no plans to have more children at 2 years after diagnosis; reproductive intentions was not associated with cancer site, stage, or treatments (39). Recently, the Dutch Childhood Oncology Group studying long-term effects after childhood cancer surveyed 1106 female survivors, median age 28.7 [IQR 12.5] for desire to have children and found that $86 \%$ reported prior, current, or future desire to have children. Cancer diagnosis, age at diagnosis, and cancer treatments (gonadotoxic radiation, alkylating chemotherapy, both or neither) were not associated with desire for future children (41). Among these studies, the proportions of survivors who do not plan to have future children are highly variable, because of heterogeneity in the age of the populations, assessment of future versus ever having reproductive intentions, and inclusion of parous women. Of note, it is possible that our exposures of interest were no longer significantly associated with voluntary childlessness in the adjusted analyses due to limited power. Similarly, self-reported chemotherapy was associated with lower likelihood of reporting voluntary childlessness in unadjusted analysis but not in adjusted analysis; moreover, this variable is less specific to gonadotoxicity than medical record derived treatment toxicity due to limitations in participant recall (24).

Interestingly, these findings stand in contrast to other chronic diseases where disease burden is related to voluntary childlessness (17-20). Qualitative and quantitative studies of cancer survivors report motivations for having children after cancer including achieving age-related milestones, hope and desire to focus on something positive, and importance for the partner (3). We speculate that in a cohort of post-treatment survivors who have overall low current co-morbidities, these motivations outweigh their historical cancer treatments.

This study has several strengths. Firstly, we present data on the AYA survivor population, for which less is known about reproductive intentions and for which there are biological and psychosocial contexts that distinguish them from younger and older groups. We used accurate treatment data from primary medical records and did not rely solely on participant reporting of cancer diagnosis and treatments, in an effort to minimize misclassification of exposures (24). Lastly, this study included a sizeable cohort largely recruited from state cancer registries to increase representativeness of the AYA population.

The study may be subject to selection bias, such that participants who are interested in having future children were more likely to enroll in a study on reproductive health and fertility after cancer. This may have led to an underestimation of the proportion of voluntarily childless AYA survivors in our population. Additionally, most participants were Caucasian and highly educated, limiting generalizability. According to the 2012 National Survey of Family Growth, 32\% of all reproductive-aged women completed college (15). In contrast, voluntarily childless women, $6 \%$ of the population, were more likely to complete college $(42 \%)$. Although our AYA population had a higher proportion of women who completed college (79\%), it is unlikely that the $22 \%$ voluntarily childlessness found in our study is largely attributable to confounding by education. Another limitation was the crosssectional nature of this analysis which precludes the ability to examine how reproductive 
intentions change over time and would benefit from longitudinal studies. Lastly, our categorization of sexual identification was modeled after the NSFG approach; this approach did not specifically assess gender identity, limiting our ability to study the association between gender identity and reproductive intentions.

To conclude, our study showed that a moderate proportion of AYA cancer survivors is voluntarily childless with no significant effect of cancer type or treatment. Relevant reproductive care, including family planning, is needed to support the family building decisions of this population.

\section{Acknowledgements}

The study was funded by NIH HD080952-05. The funding organization had no role in the design and conduct of the study; collection, management, analysis, and interpretation of the data; preparation, review, or approval of the manuscript; and decision to submit the manuscript for publication. H.I. Su had full access to all the data in the study and takes responsibility for the integrity of the data and accuracy of the data analysis.

\section{References}

1. American Cancer Society. Cancer Treatment \& Survivorship Facts \& Figures 2016-2017. Atlanta: American Cancer Society; 2016.

2. Quinn GP, Gonçalves V, Sehovic I, Bowman ML, Reed DR. Quality of life in adolescent and young adult cancer patients: a systematic review of the literature. Patient relat outcome meas. 2015;6:19. [PubMed: 25733941]

3. Schmidt R, Richter D, Sender A, Geue K. Motivations for having children after cancer-a systematic review of the literature. Euro J Cancer Care. 2016;25:6-17.

4. Syse A, Kravdal Ø, Tretli S. Parenthood after cancer-a population-based study. Psychooncology. 2007;16:920-7. [PubMed: 17279494]

5. Magelssen H, Melve KK, Skjaerven R, Fosså SD. Parenthood probability and pregnancy outcome in patients with a cancer diagnosis during adolescence and young adulthood. Hum Reprod 2007;23:178-86. [PubMed: 18024486]

6. Madanat LM, Malila N, Dyba T, Hakulinen T, Sankila R, Boice JD Jr, et al. Probability of parenthood after early onset cancer: a population-based study. Int J Cancer. 2008;123:2891-8. [PubMed: 18798259]

7. Cvancarova M, Samuelsen SO, Magelssen H, Fossa SD. Reproduction rates after cancer treatment: experience from the Norwegian radium hospital. J Clinical Oncol 2009;27:334-43. [PubMed: 19075285]

8. Green DM, Kawashima T, Stovall M, Leisenring W, Sklar CA, Mertens AC, et al. Fertility of female survivors of childhood cancer: a report from the childhood cancer survivor study. J Clinical Oncol 2009;27:2677. [PubMed: 19364965]

9. Barton SE, Najita JS, Ginsburg ES, Leisenring WM, Stovall M, Weathers RE, et al. Infertility, infertility treatment, and achievement of pregnancy in female survivors of childhood cancer: a report from the Childhood Cancer Survivor Study cohort. Lancet Oncol 2013;14:873-81. [PubMed: 23856401]

10. Chow EJ, Stratton KL, Leisenring WM, Oeffinger KC, Sklar CA, Donaldson SS, et al. Pregnancy after chemotherapy in male and female survivors of childhood cancer treated between 1970 and 1999: a report from the Childhood Cancer Survivor Study cohort. Lancet Oncol 2016;17:567-76. [PubMed: 27020005]

11. Gorman JR, Su HI, Pierce JP, Roberts SC, Dominick SA, Malcarne VL. A multidimensional scale to measure the reproductive concerns of young adult female cancer survivors. J Cancer Surviv 2014;8:218-28. [PubMed: 24352870] 
12. Wenzel L, Dogan-Ates A, Habbal R, Berkowitz R, Goldstein DP, Bernstein M, et al. Defining and measuring reproductive concerns of female cancer survivors. J. Natl Cancer Inst Monogr 2005;2005:94-8.

13. Zebrack BJ, Casillas J, Nohr L, Adams H, Zeltzer LK. Fertility issues for young adult survivors of childhood cancer. Psychooncology. 2004;13:689-99. [PubMed: 15386645]

14. Schover LR. Psychosocial aspects of infertility and decisions about reproduction in young cancer survivors: a review. Med Pediatr Oncol 1999;33:53-9. [PubMed: 10401498]

15. Martinez G, Daniels K, Chandra A. Fertility of men and women aged 15-44 years in the United States; National Survey of Family Growth, 2006-2010.

16. Riskind RG, Patterson CJ. Parenting intentions and desires among childless lesbian, gay, and heterosexual individuals. J Family Psychol 2010;24:78.

17. Ferraro D, Simone AM, Adani G, Vitetta F, Mauri C, Strumia S, et al. Definitive childlessness in women with multiple sclerosis: a multicenter study. Neuro Sci 2017;38:1453-9.

18. Alwan S, Yee IM, Dybalski M, Guimond C, Dwosh E, Greenwood TM, et al. Reproductive decision making after the diagnosis of multiple sclerosis. Mult Scle 2013;19:351-8.

19. Marri SR, Ahn C, Buchman AL. Voluntary childlessness is increased in women with inflammatory bowel disease. Inflamm bowel dis 2007;13:591-9. [PubMed: 17206690]

20. Huang VW, Chang HJ, Kroeker KI, Goodman KJ, Hegadoren KM, Dieleman LA, et al. Does the level of reproductive knowledge specific to inflammatory bowel disease predict childlessness among women with inflammatory bowel disease?. Can J of Gastroenterol Hepatol 2015;29:95103. [PubMed: 25803020]

21. Portanti M, Whitworth S. A comparison of the characteristics of childless women and mothers in the ONS Longitudinal Study. Popul Trends 2009;136:10-20.

22. Centers for Medicare and Medicaid Services [Internet]. Baltimore; 2018 [cited 2019 Aug 17]. National Survey of Family Growth (NSFG) - Years Survey Included Sexual and Gender Minority (SGM)-related Questions. Available from: https://www.cms.gov/About-CMS/AgencyInformation/OMH/resource-center/hcps-and-researchers/data-tools/sgm-clearinghouse/nsfg.html.

23. Van Dorp W, Haupt R, Anderson RA, Mulder RL, Van den Heuvel-Eibrink MM, Van Dulmen-den Broeder E, et al. Reproductive function and outcomes in female survivors of childhood, adolescent, and young adult cancer: A review. J Clin Oncol 2018;36:2169-80. [PubMed: 29874135]

24. Roberts SC, Knight A, Whitcomb BW, Gorman JR, Dietz AC, Su HI. Validity of self-reported fertility-threatening cancer treatments in female young adult cancer survivors. J Cancer Surv 2017;11:517-23.

25. IBM Corp. Released 2017. IBM SPSS Statistics for Windows, Version 25.0. Armonk, NY: IBM Corp.

26. Oktay K, Harvey BE, Partridge AH, Quinn GP, Reinecke J, Taylor HS, et al. Fertility preservation in patients with cancer: ASCO clinical practice guideline update. J Clin Oncol 2018;36:19942001. [PubMed: 29620997]

27. Quinn MM, Letourneau JM, Rosen MP. Contraception after cancer treatment: describing methods, counseling, and unintended pregnancy risk. Contra

28. ception 2014;89:466-71.

29. Medica AC, Stark SS, Hadnott TN, Dietz AC, Romero SA, Natarajan L, et al. Use of emergency contraception among female young adult cancer survivors. Fertil Steril 2018;109:1114-20. [PubMed: 29935646]

30. Hadnott TN, Stark SS, Medica A, Dietz AC, Martinez ME, Whitcomb BW, et al. Perceived infertility and contraceptive use in the female, reproductive-age cancer survivor. Fertil Steril 2019;111:763-71. [PubMed: 30929732]

31. Gorman JR, Usita P, Madlensky L, Pierce JP. Young breast cancer survivors: their perspectives on treatment decisions and fertility concerns. Cancer Nurs 2011;34:32. [PubMed: 20697269]

32. Gorman JR, Bailey S, Pierce JP, Su HI. How do you feel about fertility and parenthood? The voices of young female cancer survivors. J Cancer Surviv 2012;6:200-9. [PubMed: 22179785]

33. Shliakhtsitsava K, Suresh D, Hadnott T, Su HI. Best practices in counseling young female cancer survivors on reproductive health. Semin Reprod Med 2017;35:378-89. [PubMed: 29036745] 
34. Signorello LB, Mulvihill JJ, Green DM, Munro HM, Stovall M, Weathers RE, et al. Congenital anomalies in the children of cancer survivors: a report from the childhood cancer survivor study. $\mathrm{J}$ Clin Oncol 2012;30:239. [PubMed: 22162566]

35. Sankila R, Olsen JH, Anderson H, Garwicz S, Glattre E, Hertz H, et al. Risk of cancer among offspring of childhood-cancer survivors. N Engl J Med 1998;338:1339-44. [PubMed: 9571253]

36. Winther JF, Boice JD Jr, Mulvihill JJ, Stovall M, Frederiksen K, Tawn EJ, et al. Chromosomal abnormalities among offspring of childhood-cancer survivors in Denmark: a population-based study. Am J Hum Genet 2004;74:1282-5. [PubMed: 15106125]

37. Fiori F, Rinesi F, Graham E. Choosing to remain childless? A comparative study of fertility intentions among women and men in Italy and Britain. Eur J Popul 2017;33:319-50. [PubMed: 28725098]

38. D'Augelli AR, Rendina HJ, Sinclair KO, Grossman AH. Lesbian and gay youth's aspirations for marriage and raising children. J LGBT Issues Couns 200;1:77-98.

39. Russell AM, Galvin KM, Harper MM, Clayman ML. A comparison of heterosexual and LGBTQ cancer survivors' outlooks on relationships, family building, possible infertility, and patient-doctor fertility risk communication. J Canc Surviv 2016;10:935-42.

40. Gates G, Badgett MV, Macomber JE, Chambers K. Adoption and foster care by gay and lesbian parents in the United States. 2007.

41. Mancini J, Rey D, Préau M, Le Corroller-Soriano AG, Moatti JP. Barriers to procreational intentions among cancer survivors 2 years after diagnosis: a French national cross-sectional survey. Psycho-Oncology. 2011;20:12-8. [PubMed: 20151410]

42. Van Dijk M, Van Den Berg MH, Overbeek A, Lambalk CB, van den Heuvel-Eibrink MM, Tissing WJ, et al. Reproductive intentions and use of reproductive health care among female survivors of childhood cancer. Hum Reprod 2018;33:1167-74. [PubMed: 29617794] 
Table 1:

Cancer characteristics and voluntary childlessness in female AYA survivors $(n=413)$

\begin{tabular}{|c|c|c|c|c|}
\hline & Total, n $(\%)(n=413)$ & $\begin{array}{l}\text { Voluntarily childless, } \\
(\mathbf{n}=90)\end{array}$ & $\begin{array}{l}\text { Desires future children, } \mathbf{n}(\%) \\
\qquad(\mathrm{n}=\mathbf{3 2 3})\end{array}$ & p-value \\
\hline Cancer Type & & & & 0.31 \\
\hline Thyroid, skin & $94(22.7)$ & 25 (26.6) & $69(73.4)$ & \\
\hline Breast & $108(26.2)$ & $24(22.2)$ & $84(77.8)$ & \\
\hline Gynecologic, gastrointestinal & $41(9.9)$ & $11(26.8)$ & $30(73.2)$ & \\
\hline Blood, bone, soft tissue & $170(41.2)$ & $30(17.6)$ & $140(82.4)$ & \\
\hline Surgery & & & & 0.05 \\
\hline Yes & $272(65.9)$ & $67(24.6)$ & $205(75.4)$ & \\
\hline No & $141(34.1)$ & $23(16.3)$ & $118(83.7)$ & \\
\hline Chemotherapy & & & & 0.01 \\
\hline Yes & $285(69.0)$ & $52(18.2)$ & $233(81.8)$ & \\
\hline No & $128(31.0)$ & $38(29.7)$ & $90(70.3)$ & \\
\hline Radiation & & & & 0.17 \\
\hline Yes & $130(31.5)$ & $23(17.7)$ & $107(82.3)$ & \\
\hline No & $283(68.5)$ & $67(23.7)$ & $216(76.3)$ & \\
\hline Gonadotoxic treatments & & & & 0.02 \\
\hline Yes & $299(72.4)$ & $56(18.7)$ & $243(81.3)$ & \\
\hline No & $114(27.6)$ & $34(29.8)$ & $80(70.2)$ & \\
\hline Number of comorbidities & & & & 0.50 \\
\hline None & $109(26.4)$ & $20(18.3)$ & 89 (81.7) & \\
\hline 1 & $238(57.6)$ & $53(22.3)$ & $185(77.7)$ & \\
\hline$\geq 2$ & $66(16.0)$ & $17(25.8)$ & $49(74.2)$ & \\
\hline
\end{tabular}


Table 2:

Demographic and reproductive characteristics voluntary childlessness in female AYA survivors $(n=413)$

\begin{tabular}{|c|c|c|c|c|}
\hline & Total, $n(\%)(n=413)$ & Voluntarily childless, $\mathbf{n}(\%)(\mathrm{n}=90)$ & $\begin{array}{l}\text { Desires future children, } \mathrm{n}(\%) \\
(\mathrm{n}=\mathbf{3 2 3})\end{array}$ & p-value \\
\hline Enrollment age & & & & $<0.01$ \\
\hline $18-24$ & $38(9.2)$ & $1(2.6)$ & $37(97.4)$ & \\
\hline $25-35$ & $289(70.0)$ & $54(18.4)$ & $235(81.6)$ & \\
\hline $36-40$ & $86(20.8)$ & $35(40.7)$ & $51(59.3)$ & \\
\hline Race & & & & 0.97 \\
\hline White & $302(73.1)$ & $66(21.9)$ & $236(78.1)$ & \\
\hline Asian & $33(8.0)$ & $7(21.2)$ & $26(78.8)$ & \\
\hline African American & $13(3.1)$ & $2(15.4)$ & $11(84.6)$ & \\
\hline Other & $65(15.7)$ & $15(23.1)$ & $50(76.9)$ & \\
\hline Hispanic & & & & 0.46 \\
\hline Yes & $80(19.4)$ & $15(18.8)$ & $65(81.3)$ & \\
\hline No & $333(80.6)$ & $75(22.5)$ & $258(77.5)$ & \\
\hline Education & & & & 0.83 \\
\hline Less than college & $86(20.8)$ & $18(20.9)$ & $68(79.1)$ & \\
\hline More than college & $327(79.2)$ & $72(22.0)$ & $255(78.0)$ & \\
\hline Income & & & & 0.40 \\
\hline$<\$ 51,000$ & $114(27.6)$ & $28(24.6)$ & $86(75.4)$ & \\
\hline$>\$ 51,000$ & $299(72.4)$ & $62(20.7)$ & $237(79.3)$ & \\
\hline Partnered status & & & & 0.25 \\
\hline Not partnered & $189(45.8)$ & $46(24.3)$ & $143(75.7)$ & \\
\hline Partnered & $224(54.2)$ & 44 (19.6) & $180(80.4)$ & \\
\hline Sexual orientation & & & & $<0.01$ \\
\hline Heterosexual & $378(91.5)$ & $72(19.0)$ & $306(81.0)$ & \\
\hline Non-heterosexual & $35(8.5)$ & $18(51.4)$ & 17 (48.6) & \\
\hline Job status & & & & 0.82 \\
\hline Employed & $299(72.3)$ & $66(22.1)$ & $233(77.9)$ & \\
\hline Not employed & $114(27.6)$ & $24(21.1)$ & $90(78.9)$ & \\
\hline Times pregnant & & & & 0.02 \\
\hline None & $361(87.4)$ & $85(23.5)$ & $276(76.5)$ & \\
\hline$>1$ & $52(12.6)$ & $5(9.6)$ & $47(90.4)$ & \\
\hline History of adoption & & & & 0.52 \\
\hline Yes & 405 (98.0) & $89(22.0)$ & $316(78.0)$ & \\
\hline No & $8(2.0)$ & $1(12.5)$ & $7(87.5)$ & \\
\hline
\end{tabular}

Fertil Steril. Author manuscript; available in PMC 2021 February 01. 


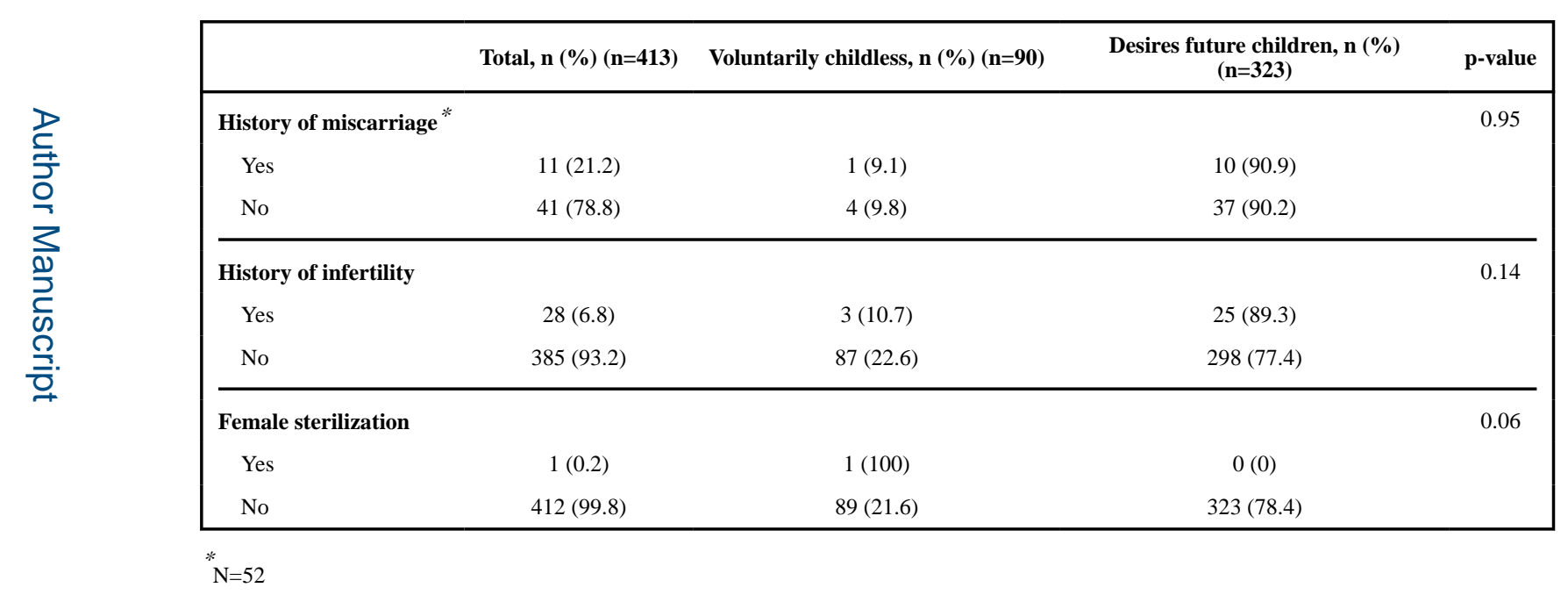


Table 3:

Unadjusted and adjusted analyses of characteristics associated with voluntary childlessness among reproductive-aged AYA survivors * $(n=413)$

\begin{tabular}{|c|c|c|c|c|}
\hline & Unadjusted OR $(95 \%$ CI) & p-value & Adjusted OR (95\% CI) & p-value \\
\hline \multicolumn{5}{|l|}{ Enrollment age } \\
\hline $18-24$ & $0.12(0.02-0.89)$ & 0.04 & $0.09(0.01-0.72)$ & 0.02 \\
\hline $25-35$ & 1 & - & 1 & - \\
\hline $36-40$ & $3.04(1.80-5.14)$ & $<0.01$ & $2.97(1.71-5.18)$ & $<0.01$ \\
\hline \multicolumn{5}{|l|}{ Gravidity } \\
\hline Nulligravida & 1 & - & 1 & - \\
\hline Multigravida & $0.35(0.133-0.90)$ & 0.03 & $0.26(0.10-0.71)$ & 0.01 \\
\hline \multicolumn{5}{|l|}{ Sexual orientation } \\
\hline Heterosexual & 1 & - & 1 & \\
\hline Non-heterosexual & $4.50(2.21-9.16)$ & $<0.01$ & $4.71(2.15-10.32)$ & $<0.01$ \\
\hline \multicolumn{5}{|c|}{ High gonadotoxic treatment } \\
\hline Yes & $0.54(0.33-0.89)$ & 0.02 & $0.60(0.35-1.02)$ & 0.06 \\
\hline No & 1 & & 1 & \\
\hline
\end{tabular}

* The adjusted model included all variables shown 
Table 4:

Unadjusted and adjusted characteristics associated with voluntary childlessness among reproductive-aged AYA survivors $^{*}(\mathrm{n}=413)$

\begin{tabular}{|c|c|c|c|c|}
\hline & Unadjusted OR (95\% CI) & p-value & Adjusted OR (95\% CI) & p-value \\
\hline \multicolumn{5}{|l|}{ Enrollment age } \\
\hline $18-24$ & $0.12(0.02-0.89)$ & 0.04 & $0.09(0.01-0.70)$ & 0.02 \\
\hline $25-35$ & 1 & - & 1 & - \\
\hline $36-40$ & $3.04(1.80-5.14)$ & $<0.01$ & $2.96(1.69-5.17)$ & $<0.01$ \\
\hline \multicolumn{5}{|l|}{ Gravidity } \\
\hline Nulligravida & 1 & - & 1 & - \\
\hline Multigravida & $0.35(0.133-0.90)$ & 0.03 & $0.25(0.09-0.68)$ & $<0.01$ \\
\hline \multicolumn{5}{|l|}{ Sexual orientation } \\
\hline Heterosexual & 1 & - & 1 & \\
\hline Non-heterosexual & $4.50(2.21-9.16)$ & $<0.01$ & $4.79(2.17-10.58)$ & $<0.01$ \\
\hline \multicolumn{5}{|l|}{ Self-reported surgery } \\
\hline Yes & $1.67(0.99-2.84)$ & 0.05 & $1.37(0.72-2.58)$ & 0.34 \\
\hline No & 1 & & 1 & \\
\hline \multicolumn{5}{|c|}{ Self-reported chemotherapy } \\
\hline Yes & $0.53(0.33-0.86)$ & 0.01 & $0.61(0.34-1.01)$ & 0.10 \\
\hline No & 1 & & 1 & \\
\hline
\end{tabular}

"The adjusted model included all variables shown 